\title{
Association Between Non-Alcoholic Fatty Liver Disease and Metabolic Syndrome with Gallstone Disease, South Iran: A Population-Based Study
}

This article was published in the following Dove Press journal: Diabetes, Metabolic Syndrome and Obesity: Targets and Therapy

\author{
Masood Sepehrimanesh \\ Ramin Niknam (D) \\ Fardad Ejtehadi (D) \\ Mohammad Reza Fattahi \\ Alireza Safarpour (iD) \\ Gastroenterohepatology Research \\ Center, Shiraz University of Medical \\ Sciences, Shiraz, Iran
}

\begin{abstract}
Aim: Gallstone disease (GSD), non-alcoholic fatty liver disease (NAFLD), and metabolic syndrome (MetS) are common problems. The aim of this study was to investigate the association between NAFLD, MetS and its components with GSD.

Materials and Methods: This cross-sectional study was conducted as a part of the Kavar Cohort Study (KCS) affiliated to Shiraz University of Medical Sciences, Shiraz, Iran between January 2012 and January 2018. A total of 2239 participants of the general population of the KCS were selected randomly. Ultrasonography for GSD and NAFLD diagnosis and clinical and laboratory assaying for MetS evaluation were performed for the participants. The National Cholesterol Education Program Adult Treatment Panel III (NCEP/ATP-III) and Criteria for Clinical Diagnosis of MetS in Iranian Adults (CCDMIA) were used for diagnosis of MetS.

Results: Overall, 59 patients with GSD and 177 age- and sex- matched participants without gallstones as a comparison group were enrolled. According to GSD groups, NAFLD was observed in $42.4 \%$ and $22.6 \%$ of patients with and without GSD, respectively, and the difference between the two groups was statistically significant $(P=0.003)$. MetS was present in $33.9 \%$ and $39.0 \%$ of GSD subjects, compared with $32.8 \%$ and $33.3 \%$ of the non-GSD group, based on NCEP/ATPIII and CCDMIA, respectively. Although the mean of all components of MetS except HDL-cholesterol were higher in the GSD group than in the nonGSD group, the difference was only significant in waist circumference $(P=0.041)$.

Conclusion: The present study found an obvious association between NAFLD and GSD. This study also showed a significant association between increasing waist circumference and risk of GSD. We recommend that patients with GSD should be evaluated for the likelihood of NAFLD and its treatment in addition to lifestyle changes to gain proper weight. However, further researches are needed to clarify the relationship between the nature of GSD, NAFLD, and obesity.
\end{abstract}

Keywords: gallstone disease, non-alcoholic fatty liver disease, metabolic syndrome, waist circumference, ultrasonography

\section{Introduction}

Gallstone disease (GSD) is a chronic recurrent hepatobiliary disease and is one of the most prevalent gastrointestinal disorders with important worldwide health concerns. ${ }^{1}$ The mechanism of GSD is the impaired metabolism of cholesterol, bilirubin and bile acids, which is characterized by the formation of gallstones in the hepatic bile duct, common bile duct, or gallbladder. ${ }^{2}$ It has different prevalence in different areas worldwide. Its prevalence is less than $5 \%$ in African countries, ${ }^{3}$ and $15 \%$ in North American population. ${ }^{4}$ In
Correspondence: Ramin Niknam Gastroenterohepatology Research Center, Shiraz University of Medical Sciences, 9th Floor, Pagooheshi Borj, Nemazee Hospital, Shiraz P. O. Box. 7|935-|3|I, Iran

Tel/Fax +98 7I3628I442

Email niknamramin@yahoo.com 
Iran, the prevalence of GSD was reported to be about $0.8 \%$ in Amol, ${ }^{5} 2.5 \%$ in Birjand, ${ }^{6}$ and $4.7 \%$ in Southern Iran. ${ }^{7}$ Risk factors for GSD have been described in previous epidemiological reports and obesity and hyperinsulinemia are the most related of these. ${ }^{8}$

Metabolic syndrome (MetS) was firstly described as the cluster of cardiovascular-related risk factors in 1988. ${ }^{9}$ Indeed, MetS includes diabetes with raised fast plasma glucose, abdominal obesity, hypertension, and hyperlipidemia. ${ }^{10}$ The Mets has high prevalence (approximately 22\%) in the general population, with differences in relation to race, gender, and age. ${ }^{11}$ Obesity, as a component of MetS is closely associated with the increased morbidity and mortality caused by several of the most common metabolic diseases including diabetes, hypertension, cardiovascular diseases, cancer, and gallstone disease (GSD). ${ }^{8,9}$ Also, when MetS occurs, the risk of cardiovascular disease and diabetes is increased 1.5-2 fold. ${ }^{12}$

Non-alcoholic fatty liver disease (NAFLD) is a common liver disease and is defined as the accumulation of triglycerides in hepatocytes without any other reason, for example, excessive alcohol consumption, viral or autoimmune hepatitis or iron overload. The presentation of NAFLD ranges from asymptomatic fatty steatosis to steatohepatitis, which can lead to fibrosis, cirrhosis, and hepatocellular carcinoma. ${ }^{13-15}$ Although liver biopsy is the gold standard for the diagnosis of NAFLD, it has known limitations, including the invasive nature of liver biopsy. Therefore, much research has been done recently on the non-invasive evaluation for diagnosis of patients with NAFLD. ${ }^{16}$ Many recent studies ${ }^{17,18}$ have been performed to assess the association between GSD and NAFLD, and they showed that GD was significantly associated with NAFLD.

There is no report from Iran on the relationship between GSD and MetS or between GSD and NAFLD. On the other hand, the high prevalence and cost of GSD, NAFLD, and MetS provide important conditions in which further studies are needed. Therefore, the purpose of this population-based study was to estimate the association of NAFLD, MetS and its components with GSD in Kavar, a city in southern Iran.

\section{Materials and Methods}

\section{Participants}

This study was conducted as part of the Kavar Cohort Study (KCS) which was started in 2006 in Kavar town. This town has a population of about 71,856 and is located 35 kilometers southeast of Shiraz, the capital of Fars province, Iran. Two research centers, the Gastroenterohepatology Research Center and Endocrine Research Center, affiliated to Shiraz University of Medical Sciences are implementing KCS. In the original cohort study, demographic and anthropometric characteristics of participants are documented in the questionnaire.

\section{Ethical Approval/Statement}

The study was conducted in accordance with the Helsinki Declaration of Ethics for Medical Research and was approved by the Ethics Committee of Shiraz University of Medical Sciences (93-01-13-7630). Written informed consent was obtained from all patients to review their medical records.

\section{Grouping}

In this cross-sectional study, 2,239 participants from the general population of KCS from both genders with no age limitation were selected randomly between January 2012 and January 2019. Ultrasonography was performed to diagnose GSD and NAFLD as well as clinical and laboratory assaying to evaluate MetS for all participants. In order to compare the GSD group with a non-GSD group, a block randomization method was used to select the age- and sexmatched group from this population.

Exclusion criteria for both GSD and non-GSD groups were history of cholecystectomy for reasons other than GSD, pregnancy, alcoholism, viral hepatitis, autoimmune hepatitis, hemochromatosis, Wilson's disease, medication use that causes hepatic steatosis (eg, anti-retroviral agents for HIV, amiodarone, methotrexate, glucocorticoids, valproate, tamoxifen), known cases of malignancy, drug-induced liver injury, cirrhosis, and non-cooperative patients because these conditions can act as confounders for our variables.

Diagnosis of GSD, NAFLD, and MetS syndrome, as well as evaluation of individual records, including exclusion criteria in both groups, were evaluated by a gastroenterologist. The interviewer, who was trained before the study, also collected and recorded various variables such as sex, age, weight, height, laboratory data on a checklist. Finally, the frequency of NAFLD and MetS components in participants with and without GSD was measured and compared.

\section{Measurements}

GSD was diagnosed by using ultrasonography. Gallstones were defined by the presence of strong intraluminal echoes that were gravity-dependent or attenuated ultrasound 
transmission. Sonograms were obtained with commercially available units using static and real-time scanning. A 3.5-MHz transducer was routinely used, with a $2.25-$ $\mathrm{MHz}$ transducer reserved for areas difficult to penetrate. The patients were examined in both supine and left posterior oblique positions, with longitudinal, transverse, and oblique scanning planes.

Waist circumference between the lowest rib and the iliac crest at the level of the umbilicus were measured in duplicate in $\mathrm{cm}$ with flexible tape. Systolic and diastolic blood pressure was measured in duplicate on the left upper arm using a random zero sphygmomanometer and the average used for analysis.

All laboratory parameters were checked under international standards in the specialized laboratory of Gastroenterohepatology Research Center. The blood specimens were transmitted to this lab in less than an hour on ice. Plasma glucose was measured by the glucoseperoxidase colorimetric enzymatic method with a sensitivity of $5 \mathrm{mg} / \mathrm{dL}$ and intra-assay coefficients of variation $(\mathrm{CV}) \mathrm{I} .7 \%$ in lower limit and $1.4 \%$ in upper limit concentrations. Inter-assay $\mathrm{CV}$ for the assay was $1.1 \%$ in lower limit and $0.6 \%$ in upper limit concentrations. Serum cholesterol and triglyceride of all the participants were measured after 12-14 hours of fasting with colorimetric method with a sensitivity of $5 \mathrm{mg} / \mathrm{dl}$. Intraassay and interassay $\mathrm{CV}$ for the assay was $1.6 \%$ and $1.1 \%$ in lower limit and $0.6 \%$ and $0.9 \%$ for upper limit concentrations, respectively. High-density lipoproteincholesterol (HDL-cholesterol) was measured after precipitation of the apolipoprotein B containing lipoproteins with phosphotungstic acid (Pars azmoon kit, Iran).

\section{MetS Criteria}

Two different criteria, namely the National Cholesterol Education Program Adult Treatment Panel III (NCEP/ ATP-III) ${ }^{19,20}$ and Criteria for Clinical Diagnosis of MetS in Iranian Adults (CCDMIA), ${ }^{21}$ were used for diagnosis of MetS. In both criteria, the MetS was defined as the presence of three or more of the components presented in Table 1.

\section{NAFLD Definition}

Diagnosis of NAFLD was made based on demonstration of hyper-echogenicity areas on sonography examination. The severity of NAFLD on sonography was divided as follows: grade 1, slight and diffuse increase in echoes of liver parenchyma with normal visualization of intrahepatic
Table I Two Criteria for Clinical Diagnosis of Metabolic Syndrome (MetS) Which were Used in This Study

\begin{tabular}{|l|l|l|}
\hline \multirow{2}{*}{ Measures } & \multicolumn{2}{|l|}{ MetS Criteria } \\
\cline { 2 - 3 } & NCEP/ATP-III & CCDMIA \\
\hline $\begin{array}{l}\text { Waist } \\
\text { circumference }\end{array}$ & $\begin{array}{l}>102 \text { and }>88 \mathrm{~cm} \text { in men } \\
\text { and women }\end{array}$ & $\begin{array}{l}\geq 95 \mathrm{~cm} \text { in both } \\
\text { genders }\end{array}$ \\
\hline Triglyceride & $\geq 150 \mathrm{mg} / \mathrm{dL}$ & $\geq 150 \mathrm{mg} / \mathrm{dL}$ \\
\hline $\begin{array}{l}\text { High density } \\
\text { lipoprotein }\end{array}$ & $\begin{array}{l}<40 \text { and }<50 \mathrm{mg} / \mathrm{dL} \text { in } \\
\text { men and women }\end{array}$ & $\begin{array}{l}<40 \text { and }<50 \mathrm{mg} / \mathrm{dL} \\
\text { in men and women }\end{array}$ \\
\hline $\begin{array}{l}\text { Blood pressure } \\
\text { SBP/DBP } \geq 130 / 85 \mathrm{mmHg}\end{array}$ & $\begin{array}{l}\text { SBP/DBP } \geq 130 / 85 \\
\mathrm{mmHg}\end{array}$ \\
\hline $\begin{array}{l}\text { Fasting blood } \\
\text { sugar }\end{array}$ & $\geq 110 \mathrm{mg} / \mathrm{dL}$ & $\geq 100 \mathrm{mg} / \mathrm{dL}$ \\
\hline
\end{tabular}

Abbreviations: NCEP/ATP-III, National Cholesterol Education Program Adult Treatment Panel III; CCDMIA, Criteria for Clinical Diagnosis of MetS in Iranian Adults; SBP, systolic blood pressure; DBP, diastolic blood pressure.

vessel borders and diaphragm; grade 2, moderate and diffuse increase in echoes of liver parenchyma with slightly impaired visualization of diaphragm and intrahepatic vessels; grade 3, marked increase in echoes of liver parenchyma with poor or non-visualization of intrahepatic vessel borders, diaphragm, and posterior right lobe of the liver. $^{22}$ Laboratory data of each NAFLD were evaluated to exclude other diseases such as viral hepatitis, autoimmune hepatitis, hemochromatosis, and Wilson's disease. As mentioned earlier, participants were excluded by the following criteria: viral hepatitis, autoimmune hepatitis, hemochromatosis, Wilson's disease, medication use that causes hepatic steatosis (eg, anti-retroviral agents for HIV, amiodarone, methotrexate, glucocorticoids, valproate, tamoxifen), known cases of malignancy, druginduced liver injury, cirrhosis, pregnancy, and history of alcoholism.

\section{Statistical Analysis}

The data were stored in a computer database and missing values and data entry errors were checked. All qualitative data were expressed as frequency and percentage. Analysis of the relationship between GSD and MetS and its component were performed using Chi-Square test. Quantitative data were expressed as mean and standard deviation (SD) and their differences between two groups were studied using two independent sample $t$-tests. A $P$ value lower than 0.05 was considered as a significant difference. 


\section{Results}

Overall, of the 2,239 participants from the general population, 59 and 177 participants with and without GSD were included in this study, respectively. The GSD to comparison group ratio was 1:3 and these two groups were ageand sex-matched (Figure 1).

In the GSD group, there were $51(86.4 \%)$ women and 8 $(13.6 \%)$ men with a mean age of $49.78 \pm 16.15$ years. The comparison group consisted of $138(78.0 \%)$ women and 39 $(22.0 \%)$ men with a mean age of $51.52 \pm 17.11$ years. No significant differences existed between the two groups neither in age $(P=0.494)$ nor in sex $(P=0.158)$. BMI was significantly higher in the GSD group than in the non-GSD group
$(P=0.022)$. Baseline demographic and clinical characteristics of enrolled GSD and non-GSD participants are shown in Table 2 .

Overall, according to NCEP/ATPIII $(P=0.873)$ and CCDMIA $(P=0.430)$ criteria, there was no significant association between MetS and existence of GSD (Table 2). Comparison of the mean and SD of each MetS components in GSD and comparison groups are presented in Table 3. Although the mean of all components of MetS except HDL-cholesterol were higher in the GSD group than in the comparison group, the difference was only significant in WC $(91.14 \pm 13.48 \mathrm{~cm}$ in the GSD group vs $87.24 \pm 12.36 \mathrm{~cm}$ in the comparison group, $P=0.041$ ).

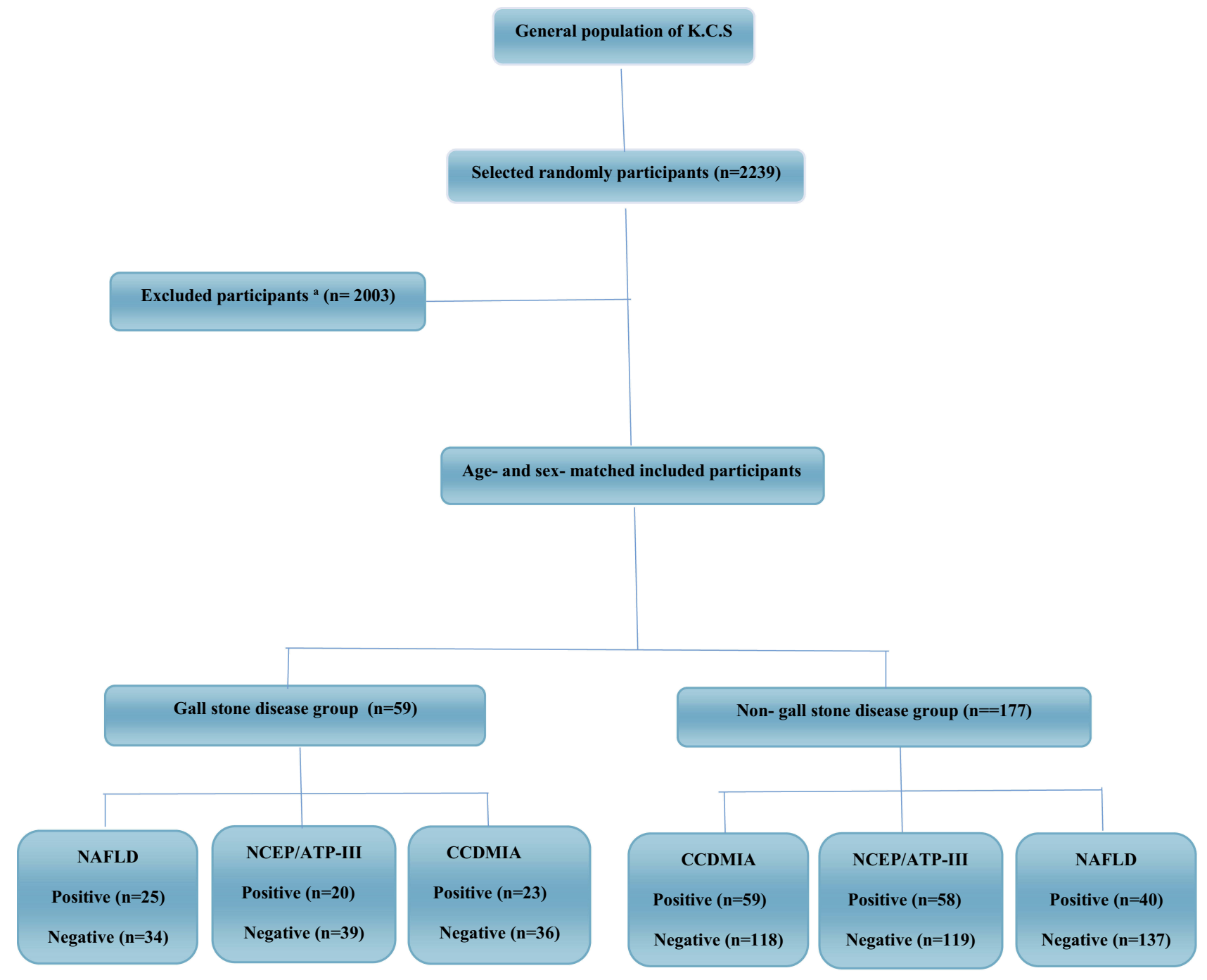

Figure I Flow diagram for the participants' selection process.

Notes: ${ }^{a}$ Participants with history of cholecystectomy, pregnancy, alcoholism, viral hepatitis, auto immune hepatitis, Hemochromatosis, Wilson disease, medication use that causes hepatic steatosis (eg, anti-retroviral agents for HIV, amiodarone, methotrexate, glucocorticoids, valproate, and tamoxifen), known cases of malignancy, drug-induced liver injury, cirrhosis, and non-cooperative patients were excluded.

Abbreviations: K.C.S, Kavar Cohort Study; MetS, metabolic syndrome; NCEP/ATP-III, National Cholesterol Education Program Adult Treatment Panel III; CCDMIA, Criteria for Clinical Diagnosis of MetS in Iranian Adults; NAFLD, non-alcoholic fatty liver disease. 
Table 2 Baseline Demographic and Clinical Characteristics of Enrolled Gallstone Disease (GSD) $(n=59)$ and Non- GSD Participants ( $\mathrm{N}=177)$

\begin{tabular}{|l|l|l|l|}
\hline Variables & $\begin{array}{l}\text { GSD Group; } \\
\text { N (\%) }\end{array}$ & $\begin{array}{l}\text { Non-GSD Group; } \\
\text { N (\%) }\end{array}$ & P-value \\
\hline $\begin{array}{l}\text { Gender } \\
\text { Female } \\
\text { Male }\end{array}$ & $\begin{array}{l}51(86.4 \%) \\
8(13.6 \%)\end{array}$ & $\begin{array}{l}138(78.0 \%) \\
39(22.0 \%)\end{array}$ & 0.158 \\
\hline Age $^{\text {b years })}$ & $49.78(16.15 \%)$ & $51.53(17.11 \%)$ & 0.494 \\
\hline $\begin{array}{l}\text { Body mass } \\
\text { index }{ }^{c}\left(k g / m^{2}\right)\end{array}$ & $26.68(4.77 \%)$ & $25.17(4.57 \%)$ & 0.022 \\
\hline $\begin{array}{l}\text { Education } \\
\text { Elementary } \\
\text { High school } \\
\text { Diploma } \\
\text { Bachelor }^{a}\end{array}$ & $\begin{array}{l}2(3.4 \%) \\
(10.2 \%)\end{array}$ & $\begin{array}{l}146(82.4 \%) \\
16(9.0 \%)\end{array}$ & 0.708 \\
\hline $\begin{array}{l}\text { NCEP/ATP-III } \\
\text { criteria }^{a}\end{array}$ & $20(33.4 \%)$ & $13(7.3 \%)$ & 0.873 \\
\hline CCDMIA criteria $^{\mathrm{a}}$ & $23(39.0 \%)$ & $59(32.8 \%)$ & 0.430 \\
\hline NAFLD $^{\mathrm{a}}$ & $25(42.4 \%)$ & $40(22.6 \%)$ & 0.003 \\
\hline
\end{tabular}

Notes:t ${ }^{a}$ Chi-square Test. ${ }^{b}$ Mean (standard deviation); $t$-test. ${ }^{c}$ Mean (standard deviation); Mann-Whitney test

Abbreviations: NCEP/ATP-III, National Cholesterol Education Program Adult Treatment Panel III; CCDMIA, Criteria for Clinical Diagnosis of MetS in Iranian Adults; NAFLD, non-alcoholic fatty liver disease.

The comparison between each component of MetS and presence of GSD, based on NCEP/ATP-III and CCDMIA criteria, are presented in Table 4. As demonstrated, only increasing waist circumference in both criteria showed a significant association with increasing of GSD $(P=$ 0.013 and $P=0.022$, for NCEP/ATP-III and CCDMIA, respectively).

Overall, 65 patients $(27.5 \%)$ had NAFLD of which $63.1 \%, 32.3 \%$, and $4.6 \%$ had grade 1,2 , and 3 severities on ultrasound. As shown in Table 5, according to presence of NAFLD, the four components of MetS including WC $(P<0.001)$, FBS $(P=0.005)$, triglycerides $(P<0.001)$, systolic blood pressure $(P=0.004)$, and diastolic blood pressure $(P<0.001)$ were significantly higher in NAFLD participants than in the non-NAFLD group. HDLcholesterol was also higher in the non-NAFLD group but the difference was not significant $(P=0.474)$.

According to the GSD groups, NAFLD was observed in $25(42.4 \%)$ and $40(22.6 \%)$ of patients with and without GSD, respectively, and the difference between the two groups was statistically significant $(P=0.003)$. Frequency of different types of NAFLD severity was higher in the GSD group than in the comparison group but this
Table 3 The Comparison of Metabolic Syndrome (MetS) Components Between Gallstone Disease (GSD) and Non- GSD Groups

\begin{tabular}{|c|c|c|c|}
\hline MetS Components & Groups & $\begin{array}{l}\text { Mean } \pm \text { Standard } \\
\text { Deviation }\end{array}$ & P-value* \\
\hline \multirow[t]{2}{*}{ Waist circumference $(\mathrm{cm})$} & GSD & $91.14 \pm 13.48$ & \multirow[t]{2}{*}{0.041} \\
\hline & Non-GSD & $87.24 \pm 12.36$ & \\
\hline \multirow{2}{*}{$\begin{array}{l}\text { Systolic blood pressure } \\
(\mathrm{mmHg})\end{array}$} & GSD & $120.59 \pm 21.62$ & \multirow[t]{2}{*}{0.976} \\
\hline & Non-GSD & $120.48 \pm 25.52$ & \\
\hline \multirow{2}{*}{$\begin{array}{l}\text { Diastolic blood pressure } \\
(\mathrm{mmHg})\end{array}$} & GSD & $77.03 \pm 12.53$ & \multirow[t]{2}{*}{0.102} \\
\hline & Non-GSD & $74.04 \pm 12.01$ & \\
\hline \multirow{2}{*}{$\begin{array}{l}\text { High density lipoprotein } \\
(\mathrm{mg} / \mathrm{dL})\end{array}$} & GSD & $44.50 \pm 10.69$ & \multirow[t]{2}{*}{0.152} \\
\hline & Non-GSD & $47.20 \pm 11.78$ & \\
\hline \multirow[t]{2}{*}{ Triglycerides (mg/dL) } & GSD & $137.22 \pm 103.81$ & \multirow[t]{2}{*}{0.451} \\
\hline & Non-GSD & $124.18 \pm 107.91$ & \\
\hline \multirow{2}{*}{$\begin{array}{l}\text { Fasting blood sugar (mg/ } \\
\mathrm{dL} \text { ) }\end{array}$} & GSD & $98.88 \pm 27.91$ & \multirow[t]{2}{*}{0.528} \\
\hline & Non-GSD & $96.24 \pm 25.25$ & \\
\hline
\end{tabular}

Note: ${ }^{*}$-test.

difference was only significant in mild NAFLD $(P=0.008)$. In terms of gender, in the male group, NAFLD was seen in $25.0 \%$ and $17.9 \%$ of patients with and without GSD, whereas in the female group, NAFLD was observed in $45.1 \%$ and $23.9 \%$ of patients with and without GSD, respectively. The comparison of liver biochemical tests and different types of NAFLD between positive and negative GSD are shown in Table 6. ALT and AST levels in the NAFLD were significantly higher than the non-NAFLD group but the difference in GSD from non-GSD was not significant (Tables 5 and 6).

\section{Discussion}

This cross-sectional study in the general population showed a significant association between NAFLD and GSD. Also, the association between MetS and its components with GSD were evaluated based on criteria from both NCEP/ATPIII and CCDMIA. Although the mean of all MetS components was different between the GSD and non-GSD groups, this difference was significant only in waist circumference.

GSD is one of the most prevalent gastrointestinal disorders with important worldwide health concern. ${ }^{1}$ It has different prevalence in different areas worldwide. ${ }^{3}$ GSD 
Table 4 The Comparison Between Each Component of Metabolic Syndrome (MetS) and Presence of Gallstone Disease (GSD), Based on NCEP/ATP-III ${ }^{\mathrm{a}}$ and CCDMIA $^{\mathrm{b}}$ Criteria

\begin{tabular}{|c|c|c|c|c|}
\hline \multirow{2}{*}{$\begin{array}{l}\text { MetS Components; } \\
\text { N (\%) }\end{array}$} & \multirow[t]{2}{*}{ Picture } & \multicolumn{2}{|l|}{ Groups } & \multirow[t]{2}{*}{$P$-value* } \\
\hline & & GSD (59) & $\begin{array}{l}\text { Non-GSD } \\
(177)\end{array}$ & \\
\hline \multicolumn{5}{|l|}{$\begin{array}{l}\text { High Waist } \\
\text { Circumference }\end{array}$} \\
\hline \multirow[t]{2}{*}{ NCEP/ATPIII } & Yes & $35(32.7)$ & $72(67.3)$ & 0.013 \\
\hline & No & $24(18.6)$ & $105(81.4)$ & \\
\hline \multirow[t]{2}{*}{ CCDMIA } & Yes & $25(34.7)$ & $47(65.3)$ & 0.022 \\
\hline & No & $34(20.7)$ & $130(79.3)$ & \\
\hline \multicolumn{5}{|l|}{ Hyperglycemia } \\
\hline \multirow[t]{2}{*}{ NCEP/ATPIII } & Yes & $13(31.0 \%)$ & $29(69.0 \%)$ & 0.326 \\
\hline & No & $46(23.7 \%)$ & 148 (76.3\%) & \\
\hline \multirow[t]{2}{*}{ CCDMIA } & Yes & $23(30.7 \%)$ & $52(69.3 \%)$ & 0.170 \\
\hline & No & $36(22.4 \%)$ & $125(77.6 \%)$ & \\
\hline \multirow[t]{2}{*}{ Hypertension } & Yes & $29(28.4)$ & $73(7 \mid .6)$ & 0.288 \\
\hline & No & $30(22.4)$ & $104(77.6)$ & \\
\hline \multirow[t]{2}{*}{ Low HDL level } & Yes & $44(27.8 \%)$ & 114 (72.2\%) & 0.150 \\
\hline & No & $15(19.2 \%)$ & $63(80.8 \%)$ & \\
\hline \multirow[t]{2}{*}{ Hypertriglyceridemia } & Yes & $20(26.7 \%)$ & 55 (73.3\%) & 0.687 \\
\hline & No & $39(24.2 \%)$ & $122(79.2)$ & \\
\hline
\end{tabular}

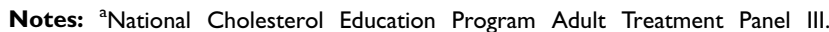
${ }^{\mathrm{b}}$ Criteria for Clinical Diagnosis of MetS in Iranian Adults. *Chi-square Test.

risk factors have been studied in previous reports that showed obesity and hyperinsulinemia are the most important associated factors. ${ }^{8}$

As seen in our study, according to the previous epidemiologic studies, women have a higher prevalence of GSD than men. It has been reported that estrogen is an obvious factor for this gender difference, ${ }^{23}$ however, the menopausal status of women and also their estrogen levels were not considered in this study. These two factors can be used as independent variables for performing other similar researches.

In a previous study in Mexico, it had been reported that the presence of high waist circumference was the most important factor associated with the risk of having GSD. ${ }^{8}$ Also, a population-based follow-up study on GSD in Taiwan showed that greater waist circumference was associated with the development of GSD among type II diabetics. ${ }^{24}$ Higher waist circumference as an indicator of abdominal obesity may
Table 5 The Comparison of Clinical and Demographic and Laboratory Data Characteristics Between Non-Alcoholic Fatty Liver Disease (NAFLD) $(n=65)$ and Non-NAFLD $(n=|7|)$ Groups

\begin{tabular}{|c|c|c|c|}
\hline Variables & NAFLD & $\begin{array}{l}\text { Non- } \\
\text { NAFLD }\end{array}$ & $P$-value \\
\hline $\begin{array}{l}\text { Gender; } \mathbf{N}(\% \text { within } \\
\text { NAFLD) } \\
\text { Female } \\
\text { Male }\end{array}$ & $\begin{array}{l}56(86.2 \%) \\
9(13.8 \%)\end{array}$ & $\begin{array}{l}133(77.8 \%) \\
38(22.2 \%)\end{array}$ & 0.150 \\
\hline Age $^{\mathrm{b}}$ (years) & $57.11(10.60)$ & 48.79 (18.22) & $<0.001$ \\
\hline Body mass index $\left(\mathrm{kg} / \mathrm{m}^{2}\right)$ & $28.80(3.902)$ & 24.31 (4.3I) & $<0.001$ \\
\hline Waist circumference ${ }^{\mathrm{b}}, \mathrm{cm}$ & $96.94(11.56)$ & $84.90(11.56)$ & $<0.001$ \\
\hline Fasting blood sugar ${ }^{c} ; \mathrm{mg} / \mathrm{dL}$ & $\begin{array}{l}101.45 \\
(24.47)\end{array}$ & $95.14(26.15)$ & 0.005 \\
\hline Aspartate transaminase ${ }^{c} ; \mathrm{IU} / \mathrm{L}$ & $28.15(21.92)$ & $17.08(8.20)$ & $<0.001$ \\
\hline Alanine transaminase ${ }^{c} ; I U / L$ & $26.88(24.91)$ & $12.44(6.86)$ & $<0.001$ \\
\hline Alkaline phosphatase ${ }^{c} ; I U / L$ & $\begin{array}{l}198.85 \\
(62.00)\end{array}$ & $\begin{array}{l}184.78 \\
(72.99)\end{array}$ & 0.052 \\
\hline Total cholesterol ${ }^{\mathrm{c}} ; \mathrm{mg} / \mathrm{dL}$ & $\begin{array}{l}190.78 \\
(44.85)\end{array}$ & $\begin{array}{l}157.05 \\
(46.20)\end{array}$ & $<0.001$ \\
\hline Triglyceride ${ }^{c} ; \mathrm{mg} / \mathrm{dL}$ & $\begin{array}{l}176.30 \\
(155.58)\end{array}$ & $\begin{array}{l}109.19 \\
(75.74)\end{array}$ & $<0.001$ \\
\hline HDL-cholesterol ${ }^{c} ; \mathrm{mg} / \mathrm{dL}$ & $45.71(11.51)$ & $46.96(11.63)$ & 0.474 \\
\hline Blood pressure & & & \\
\hline $\begin{array}{l}\text { Systolic blood pressure }{ }^{\mathrm{c}} \text {; mm } \\
\mathrm{Hg}\end{array}$ & $128.00(25.63)$ & $\begin{array}{l}117.66 \\
(23.59)\end{array}$ & 0.004 \\
\hline $\begin{array}{l}\text { Diastolic blood pressure ; mm } \\
\mathrm{Hg}\end{array}$ & $79.69(11.31)$ & $72.92(12.01)$ & $<0.001$ \\
\hline
\end{tabular}

Notes: a Chi-square Test. ${ }^{b}$ Mean (standard deviation); $t$-test. ${ }^{~}$ Mean (standard deviation); Mann-Whitney test.

play an important role in the pathophysiology of both diseases. Bray and Bellanger ${ }^{12}$ showed that as body weight rises, the risk of gall bladder disease increases. The association between obesity and cholesterol gallstones has also been studied and showed that GSD is more common in women than in men. ${ }^{25,26}$ Scheffer $^{27}$ also found in one study that obesity is a major risk factor for GSD. Chang et $\mathrm{al}^{28}$ reported that the prevalence of abdominal obesity and MetS in subjects with GSD were higher than in those without. In two other important studies, it was reported that MetS was associated with complicated GSD. ${ }^{29,30}$ As a mechanism of GSD formation, obesity is associated with increased synthesis and excretion of cholesterol into the bile. ${ }^{2}$ A low-fiber diet slows transit of the intestinal contents, which promotes the increased formation and absorption of secondary bile acids and the enhanced lithogenic properties of bile. ${ }^{31}$ On the other hand, weight loss is accompanied by the elevated levels of mucin and calcium in the cystic bile, thereby giving rise to biliary sludge and stones in the gallbladder. ${ }^{2}$ Although in our study, other 
Table 6 The Comparison of Liver Biochemical Tests and Different Types of Non-Alcoholic Fatty Liver Disease (NAFLD) Between Gallstone Disease (GSD) $(n=59)$ and Non- GSD $(n=177)$ Groups

\begin{tabular}{|c|c|c|c|}
\hline $\begin{array}{l}\text { Laboratory Data } \\
\text { Variables* }\end{array}$ & GSD & Non-GSD & $P$-value \\
\hline $\begin{array}{l}\text { NAFLD*a; N (\% within } \\
\text { GSD) }\end{array}$ & $25(42.4 \%)$ & $40(22.6 \%)$ & 0.003 \\
\hline Grade I & 17 (28.8\%) & $24(13.6 \%)$ & 0.008 \\
\hline Grade 2 & $6(10.2 \%)$ & $15(8.5 \%)$ & 0.692 \\
\hline Grade 3 & $2(3.4 \%)$ & $\mathrm{I}(0.6 \%)$ & 0.100 \\
\hline $\begin{array}{l}\text { Alanine transaminase }{ }^{\mathrm{b}} ; \mathrm{IU} / \\
\mathrm{L} /\end{array}$ & $14.78(9.26)$ & $\begin{array}{l}16.97 \\
(17.24)\end{array}$ & 0.148 \\
\hline $\begin{array}{l}\text { Aspartate transaminase }{ }^{\mathrm{b}} \text {; } \\
\text { IU/L }\end{array}$ & $18.02(8.46)$ & $\begin{array}{l}20.83 \\
(15.7 I)\end{array}$ & 0.742 \\
\hline $\begin{array}{l}\text { Alkaline phosphatase }{ }^{\mathrm{b}} \text {; IU/ } \\
\mathrm{L}\end{array}$ & $\begin{array}{l}202.17 \\
(103.87)\end{array}$ & $\begin{array}{l}184.15 \\
(54.4 I)\end{array}$ & 0.398 \\
\hline Body mass index $\left(\mathrm{kg} / \mathrm{m}^{2}\right)$ & $26.68(4.77)$ & $25.17(4.57)$ & 0.031 \\
\hline
\end{tabular}

Notes: ${ }^{a}$ Chi-square test. ${ }^{b}$ Mean (standard deviation); Mann-Whitney test. 'Mean (standard deviation); $t$-test. *The severity of NAFLD on sonography was divided as follows: grade I, slight and diffuse increase in echoes of liver parenchyma with normal visualization of intrahepatic vessel borders and diaphragm; grade 2, moderate and diffuse increase in echoes of liver parenchyma with slightly impaired visualization of diaphragm and intrahepatic vessels; grade 3 , marked increase in echoes of liver parenchyma with poor or non-visualization of intrahepatic vessel borders, diaphragm, and posterior right lobe of the liver.

MetS components except HDL-cholesterol including FBS, triglyceride, and blood pressure were higher in patients with GSD than the comparison group, there was no significant difference between the two groups. These results are in contrast to the significant association of HDL-cholesterol, ${ }^{8}$ triglyceride, and blood pressure ${ }^{32}$ reported previously.

Although a few previous studies have shown that the overall prevalence of GSD in patients with NAFLD is not significantly different from those with non-NAFLD, ${ }^{33}$ many recent studies suggest a significant association between them. ${ }^{17,18,34-38}$ In our study, there was significant association between GSD and NAFLD (Table 6). NAFLD was present in $62 \%$ of GSD patients in one observational study by Ahmed et al, ${ }^{38}$ which was higher than our report (42.4\%), also the level of LFT in their patients was higher in the NAFLD group, which was similar to our study (Table 5). Most of their GSD patients were female, which was similar to our study and may be due to differences in sex hormones and cholesterol metabolism in women. ${ }^{38}$ A cross-sectional study of 7,583 Chinese subjects showed that asymptomatic gallstones are strongly associated with NAFLD in this population, ${ }^{37}$ which is consistent with our study. Another study of the Chinese population concluded that NAFLD is associated with GSD in an urban population of middle and upper socioeconomic strata. As in our study, this association was stronger in females than in males. ${ }^{36}$ Another research, like our study results, showed that patients with metabolic risk factors and GSD were more likely to suffer from NAFLD than the reference group, and NAFLD was an independent risk factor for GSD. ${ }^{35}$ A study by Garcia-Monzon et $\mathrm{al}^{39}$ aimed to determine the prevalence of different histological manifestations of NAFLD, assessing the performance of noninvasive fibrosis markers, and evaluation of risk factors associated with biopsy-proven NASH in GSD patients. In this study, abdominal ultrasound and liver biopsy were performed on 215 consecutive patients with GSD referred to cholecystectomy. They concluded that the prevalence of NASH in GSD was lower than previously estimated, but NASH is particularly frequent in patients with concomitant MetS. A study of Turkish patients showed that GSD was associated with age, female gender, obesity, and the MetS, but not with an increased risk of NASH and significant fibrosis in patients with biopsy-proven NAFLD. ${ }^{40}$ Finally, two Systematic Reviews and Meta-Analyses ${ }^{17,18}$ have been performed to assess the association between GSD and NAFLD, which showed that GD was significantly associated with NAFLD. In addition, the occurrence of GSD is significantly associated with female gender and BMI in patient with NAFLD,${ }^{18}$ which is similar to the results of our study.

The association between GSD and severity of NAFLD has been studied in some published reports. In a cohort study of 7,886 participants, older age and higher grade of NAFLD on ultrasound were independent risk factors for GSD. ${ }^{41}$ Another cohort study of middle-aged and young participants showed that NAFLD and its severity were independently associated with increased GSD, while GSD and cholecystectomy were also associated with the incidence of NAFLD. This study concluded that these conditions may affect each other. ${ }^{42}$ A study by Lee et $\mathrm{al}^{43}$ aimed to determine the relationship between the severity of NAFLD and GSD in a Taiwanese population. They concluded that independently of the metabolic risk factor, only moderate to severe NAFLD was associated with an increased risk of GSD. Age, female gender, hypertension, and diabetes mellitus were also associated with a higher risk of GSD, but moderate alcohol consumption and lower HDL-C levels were lower risk. ${ }^{43}$ Compared with the study mentioned, the frequency of different types of NAFLD severity in our participants was higher in the GSD group than in the comparison group, but this difference was only significant in mild NAFLD (Table 6). 
The association between NAFLD and cholecystectomy has been also studied in various published reports. Analysis of data from the Third National Health and Nutrition Survey (NHANES III) showed that the magnitude of association of NAFLD with cholecystectomy was similar to central obesity. ${ }^{44}$ A cross-sectional study of 17,612 Asian subjects showed that cholecystectomy, but not GSD, was independently associated with NAFLD after adjusting for metabolic risk factors. ${ }^{45}$ The association between NAFLD and cholecystectomy, but not with GSD, suggested that cholecystectomy may itself be a risk factor for NAFLD. ${ }^{46}$ A study evaluating the prevalence of non-alcoholic steatohepatitis and metabolic syndrome in symptomatic GSD patients undergoing laparoscopic surgery or open cholecystectomy showed that $55 \%$ of these patients had biopsy-proven non-alcoholic steatohepatitis. ${ }^{47}$

There are several gut and gut-related hormones including ghrelin, glucagon-like peptide-1, peptide tyrosine tyrosine, insulin, leptin, and adiponectin. ${ }^{48}$ In some studies, the role of the gut hormone in the pathophysiology of GSD has been addressed. For instance, it has been reported that large basal plasma concentrations of pancreatic polypeptide, a gut peptide inducing gallbladder relaxation, may constitute a factor facilitating lithogenesis. ${ }^{49}$ However, assessing the amount of gutrelated hormones in the GSD patients with and without MetS is highly recommended for clarifying the underlying pathophysiology.

This is the first report to show the association of NAFLD and MetS in GSD from Iran. The main strength of our research was that our study was population-based. Other strength of our research was the appropriate inclusion and exclusion criteria for both groups to limit the influence of various confounding factors on NAFLD and MetS components. Finally, our research had the age- and sex-matched comparison group with considerable sample size. Our study suffered from important limitations. First, the sample size of patients with GSD in our study was relatively low. However, in an effort to overcome this limitation, we increased the number of age- and gender-matched comparison group as well as eliminating important confounding factors that may affect the NAFLD and the MetS by strict exclusion criteria. Second, the diagnosis of NAFLD was based only on sonography. Although liver biopsy is the gold standard for the diagnosis of NAFLD, like many researches because of the invasive nature of liver biopsy and the high cost, only sonography and liver biochemical tests were considered for diagnosis. ${ }^{15,16}$ On the other hand, although the ability to identify NAFLD patients and estimate steatofibrosis over the past years has improved with various ultrasound-based techniques including semiquantitative, quantitative, contrast-enhanced, and elastographic ultrasound techniques, further research is needed to more precisely define the role of the most innovative sonographic techniques. ${ }^{50}$ Third, we were unable to evaluate or exclude the effects of some potential confounding factors on NAFLD or Mets in participants such as physical activity and nutrition patterns.

In conclusion, the present study found an obvious association between NAFLD and GSD. It also showed a significant association between increasing waist circumference and risk of GSD. We recommend that patients with GSD should be evaluated for the likelihood of NAFLD and its treatment in addition to lifestyle changes to gain normal weight. However, the mechanism for these associations remains unclear, further researches are needed to clarify the relationship between the nature of GSD, NAFLD, and obesity.

\section{Acknowledgment}

This study was conducted as a part of the Kavar Cohort Study and was supported by the Research Council of Shiraz University of Medical Sciences, Shiraz, Iran (9301-13-7630).

\section{Disclosure}

The authors report no conflicts of interest in this work.

\section{References}

1. Marschall HU, Einarsson C. Gallstone disease. J Intern Med. 2007;261 (6):529-542. doi:10.1111/j.1365-2796.2007.01783.x

2. Reshetnyak VI. Concept of the pathogenesis and treatment of cholelithiasis. World J Hepatol. 2012;4(2):18-34. doi:10.4254/wjh. v4.i2.18

3. Miquel JF, Covarrubias C, Villaroel L, et al. Genetic epidemiology of cholesterol cholelithiasis among Chilean Hispanics, Amerindians, and Maoris. Gastroenterology. 1998;115(4):937-946. doi:10.1016/S00165085(98)70266-5

4. Stinton LM, Myers RP, Shaffer EA. Epidemiology of gallstones. Gastroenterol Clin North Am. 2010;39(2):157-169. doi:10.1016/j. gtc.2010.02.003

5. Zamani F, Sohrabi MR, Motamed N, et al. Prevalence and risk factors of cholelithiasis in Amol city, Northern Iran: a population based study. Arch Iran Med. 2014;17(11):750-754.

6. Toosi FS, Ehsanbakhsh AR, Tavakoli MR. Asymptomatic gallstones and related risk factors in Iran. Hepatogastroenterology. 2010;58 (109):1123-1126.

7. Massarrat S. Prevalence of gallstone disease in Iran. $J$ Gastroenterol Hepatol. 2001;16(5):564-567. doi:10.1046/j.1440-1746.2001.02478.x 
8. Méndez-Sánchez N, Chavez-Tapia NC, Motola-Kuba D, et al. Metabolic syndrome as a risk factor for gallstone disease. World $J$ Gastroenterol. 2005;11(11):1653-1657. doi:10.3748/wjg.v11. i11.1653

9. Reaven GM. Role of insulin resistance in human disease. Diabetes. 1988;37(12):1595-1607. doi:10.2337/diab.37.12.1595

10. Chen SH, He F, Zhou HL, Wu HR, Xia C, Li YM. Relationship between nonalcoholic fatty liver disease and metabolic syndrome. $J \quad$ Dig Dis. 2011;12(2):125-130. doi:10.1111/j.17512980.2011.00487.x

11. Marchesini G, Bugianesi E, Forlani G, et al. Nonalcoholic fatty liver, steatohepatitis, and the metabolic syndrome. Hepatology. 2003;37 (4):917-923. doi:10.1053/jhep.2003.50161

12. Bray GA, Bellanger T. Epidemiology, trends, and morbidities of obesity and the metabolic syndrome. Endocrine. 2006;29 (1):109-117. doi:10.1385/ENDO:29:1:109

13. Lazo M, Clark JM. The epidemiology of nonalcoholic fatty liver disease: a global perspective. Semin Liver Dis. 2008;28(4):339-350. doi:10.1055/s-0028-1091978

14. Milic S, Stimac D. Nonalcoholic fatty liver disease/steatohepatitis: epidemiology, pathogenesis, clinical presentation and treatment. Dig Dis. 2012;30(2):158-162. doi:10.1159/000336669

15. Koch LK, Yeh MM. Nonalcoholic fatty liver disease (NAFLD): diagnosis, pitfalls, and staging. Ann Diagn Pathol. 2018;37:83-90. doi:10.1016/j.anndiagpath.2018.09.009

16. Castera L, Friedrich-Rust M, Loomba R. Noninvasive assessment of liver disease in patients with nonalcoholic fatty liver disease. Gastroenterology. 2019;156(5):1264-81 e4. doi:10.1053/j. gastro.2018.12.036

17. Jaruvongvanich V, Sanguankeo A, Upala S. Significant association between gallstone disease and nonalcoholic fatty liver disease: a systematic review and meta-analysis. Dig Dis Sci. 2016;61 (8):2389-2396. doi:10.1007/s10620-016-4125-2

18. Shen SS, Gong JJ, Wang XW, et al. Promotional effect of nonalcoholic fatty liver disease on Gallstone disease: a systematic review and meta-analysis. Turk J Gastroenterol. 2017;28(1):31-39. doi:10.5152/ tjg.2016.0357

19. Grundy SM, Cleeman JI, Daniels SR, et al. Diagnosis and management of the metabolic syndrome: an American Heart Association/National Heart, Lung, and Blood Institute scientific statement. Circulation. 2005;112 (17):2735-2752. doi:10.1161/CIRCULATIONAHA.105.169404

20. Stone NJ, Bilek S, Rosenbaum S. Recent national cholesterol education program adult treatment panel III update: adjustments and options. Am J Cardiol. 2005;96(4):53E-9E. doi:10.1016/j. amjcard.2005.06.006

21. Azizi F, Hadaegh F, Khalili D, et al. Appropriate definition of metabolic syndrome among Iranian adults: report of the Iranian National Committee of Obesity. Arch Iran Med. 2010;13(5):426-428.

22. Saadeh S, Younossi ZM, Remer EM, et al. The utility of radiological imaging in nonalcoholic fatty liver disease. Gastroenterology. 2002;123(3):745-750. doi:10.1053/gast.2002.35354

23. Kim SS, Lee JG, Kim DW, et al. Insulin resistance as a risk factor for gallbladder stone formation in Korean postmenopausal women. Korean J Intern Med. 2011;26(3):285-293. doi:10.3904/kjim.2011.26.3.285

24. Tung TH, Ho HM, Shin HC, et al. A population-based follow-up study on gallstone disease among type 2 diabetics in Kinmen, Taiwan. World J Gastroenterol. 2006;12(28):4536-4540 doi:10.3748/wjg.v12.i28.4536

25. Grundy SM. Cholesterol gallstones: a fellow traveler with metabolic syndrome? Am J Clin Nutr. 2004;80(1):1-2. doi:10.1093/ajcn/80.1.1

26. Kern Jr F, Erfling W, Braverman D. Why more women than men have cholesterol gallstones: studies of biliary lipids in pregnancy. Trans Am Clin Climatol Assoc. 1979;90:71-75.

27. Shaffer EA. Epidemiology and risk factors for gallstone disease: has the paradigm changed in the 21 st century? Curr Gastroenterol Rep. 2005;7(2):132-140. doi:10.1007/s11894-005-0051-8
28. Chang Y, Sung E, Ryu S, Park YW, Jang YM, Park M. Insulin resistance is associated with gallstones even in non-obese, non-diabetic Korean men. J Korean Med Sci. 2008;23(4):644-650. doi: $10.3346 / \mathrm{jkms} .2008 .23 .4 .644$

29. Ata N, Kucukazman M, Yavuz B, et al. The metabolic syndrome is associated with complicated gallstone disease. Can J Gastroenterol. 2011;25(5):274-276. doi:10.1155/2011/356761

30. Pitt HA. Hepato-pancreato-biliary fat: the good, the bad and the ugly. HPB. 2007;9(2):92-97. doi:10.1080/13651820701286177

31. Ilychenko AA. Gallstone disease. Lechashchiy Vrach. 2004;4:27-33.

32. Chen LY, Qiao QH, Zhang SC, Chen YH, Chao GQ, Fang LZ. Metabolic syndrome and gallstone disease. World J Gastroenterol. 2012;18(31):4215-4220. doi:10.3748/wjg.v18.i31.4215

33. Lonardo A, Lombardini S, Scaglioni F, et al. Fatty liver, carotid disease and gallstones: a study of age-related associations. World J Gastroenterol. 2006;12(36):5826-5833. doi:10.3748/wjg.v12.i36.5826

34. Fracanzani AL, Valenti L, Russello M, et al. Gallstone disease is associated with more severe liver damage in patients with non-alcoholic fatty liver disease. PLoS One. 2012;7(7):e41183. doi:10.1371/journal.pone. 0041183

35. Koller T, Kollerova J, Hlavaty T, Huorka M, Payer J. Cholelithiasis and markers of nonalcoholic fatty liver disease in patients with metabolic risk factors. Scand J Gastroenterol. 2012;47(2):197-203. doi: $10.3109 / 00365521.2011 .643481$

36. Liu J, Lin H, Zhang C, et al. Non-alcoholic fatty liver disease associated with gallstones in females rather than males: a longitudinal cohort study in Chinese urban population. BMC Gastroenterol. 2014;14(1):213. doi:10.1186/s12876-014-0213-y

37. Qiao QH, Zhu WH, Yu YX, Huang FF, Chen LY. Nonalcoholic fatty liver was associated with asymptomatic gallstones in a Chinese population. Medicine (Baltimore). 2017;96(38):e7853. doi:10.1097/ MD.0000000000007853

38. Ahmed F, Baloch Q, Memon ZA, Ali I. An observational study on the association of nonalcoholic fatty liver disease and metabolic syndrome with gall stone disease requiring cholecystectomy. Ann Med Surg. 2017;17:7-13. doi:10.1016/j.amsu.2017.03.015

39. Garcia-Monzon C, Vargas-Castrillon J, Porrero JL, et al. Prevalence and risk factors for biopsy-proven non-alcoholic fatty liver disease and non-alcoholic steatohepatitis in a prospective cohort of adult patients with gallstones. Liver Int. 2015;35(8):1983-1991. doi:10.1111/liv.12813

40. Yilmaz Y, Ayyildiz T, Akin H, et al. Gallstone disease does not predict liver histology in nonalcoholic fatty liver disease. Gut Liver. 2014;8(3):313-317. doi:10.5009/gnl.2014.8.3.313

41. Kim YK, Kwon OS, Her KH. The grade of nonalcoholic fatty liver disease is an independent risk factor for gallstone disease: an observational study. Medicine (Baltimore). 2019;98(27):e16018. doi:10.1097/MD.0000000000016018

42. Chang Y, Noh YH, Suh BS, et al. Bidirectional association between nonalcoholic fatty liver disease and gallstone disease: a cohort study. J Clin Med. 2018;7(11):458. doi:10.3390/jcm7110458

43. Lee YC, Wu JS, Yang YC, Chang CS, Lu FH, Chang CJ. Moderate to severe, but not mild, nonalcoholic fatty liver disease associated with increased risk of gallstone disease. Scand J Gastroenterol. 2014;49 (8):1001-1006. doi:10.3109/00365521.2014.920912

44. Yue W, Sun X, Du T. Cholecystectomy versus central obesity or insulin resistance in relation to the risk of nonalcoholic fatty liver disease: the third US National Health and Nutrition Examination Survey. BMC Endocr Disord. 2019;19(1):95. doi:10.1186/s12902019-0423-y

45. Kwak MS, Kim D, Chung GE, Kim W, Kim YJ, Yoon JH. Cholecystectomy is independently associated with nonalcoholic fatty liver disease in an Asian population. World J Gastroenterol. 2015;21(20):6287-6295. doi:10.3748/wjg.v21.i20.6287

46. Ruhl CE, Everhart JE. Relationship of non-alcoholic fatty liver disease with cholecystectomy in the US population. Am J Gastroenterol. 2013;108(6):952-958. doi:10.1038/ajg.2013.70 
47. Yener O, Aksoy F, Demir M, Ozcelik A, Erengul C. Gallstones associated with nonalcoholic steatohepatitis (NASH) and metabolic syndrome. Turk J Gastroenterol. 2010;21(4):411-415. doi:10.4318/ tjg. 2010.0128

48. Finelli C, Padula MC, Martelli G, Tarantino G. Could the improvement of obesity-related co-morbidities depend on modified gut hormones secretion? World J Gastroenterol. 2014;20(44):16649-16664. doi:10.3748/wjg.v20.i44.16649
49. Montet JC, Caroli-Bosc FX, Ferrari P, et al. Gallbladder motility and gut hormone plasma levels in subjects with and without gallstones. Gastroenterol Clin Biol. 2005;29(5):569-572. doi:10.1016/S03998320(05)82131-1

50. Ballestri S, Nascimbeni F, Lugari S, Lonardo A, Francica G. A critical appraisal of the use of ultrasound in hepatic steatosis. Expert Rev Gastroenterol Hepatol. 2019;13(7):667-681. doi:10.1080/17474124. 2019.1621164

\section{Publish your work in this journal}

Diabetes, Metabolic Syndrome and Obesity: Targets and Therapy is an international, peer-reviewed open-access journal committed to the rapid publication of the latest laboratory and clinical findings in the fields of diabetes, metabolic syndrome and obesity research. Original research, review, case reports, hypothesis formation, expert opinion and commentaries are all considered for publication. The manuscript management system is completely online and includes a very quick and fair peer-review system, which is all easy to use. Visit http://www.dovepress.com/testimonials.php to read real quotes from published authors. 